BRIEF REPORT

\title{
Differential ranking of causes of fatal versus non-fatal injuries among US children
}

\author{
M F Ballesteros, R A Schieber, J Gilchrist, P Holmgreen, J L Annest
}

Injury Prevention 2003;9:173-176

See end of article for authors' affiliations

\section{Correspondence to:}

Dr Michael F Ballesteros,

Division of Unintentional

Injury Prevention, National

Center for Injury Prevention

and Control, Centers for

Disease Control and

Prevention, 4770 Buford

Highway, NE, Mailstop

K-63, Atlanta, GA 30341

USA;

mballesteros@cdc.gov

\begin{abstract}
Objective: Leading causes of fatal and non-fatal injury among US children aged $<15$ years were compared.

Method: A descriptive study was conducted using nationally representative data on injury related deaths (National Vital Statistics System) and on non-fatal injury related emergency department visits (IEDV; National Electronic Injury Surveillance System-All Injury Program). Data were accessed using a publicly available web based system.

Results: Annually, an estimated 7100000 pediatric IEDV and 7400 injury deaths occurred. The overall non-fatal to fatal ratio (NF:F) was 966 IEDV: 1 death. Among deaths, the leading causes were motor vehicle traffic occupants $(n=1700 ; N F: F=150: 1)$, suffocations ( $n=1037 ; N F: F=14: 1)$, and drownings $(n=971, N F: F=6: 1)$. Among non-fatal injuries, falls (estimated 2400000$)$ and struck by/against (estimated 1800 000) were the most common causes, but substantially less lethal (NF:F = 19 000:1 and 15 000:1, respectively).

Conclusions: The leading causes of pediatric fatal and non-fatal injuries differed substantially. This study indicates the need for consideration of common causes of non-fatal injury, especially falls.
\end{abstract}

\section{METHODS}

Data were obtained from the Web based Injury Statistics and Query System (WISQARS), a Centers for Disease Control and Prevention (CDC) web based interactive platform recently enhanced to include non-fatal injuries (http://www.cdc.gov/ ncipc/wisqars). WISQARS allows for querying by age, race/ethnicity, sex, state (fatal data only), year, injury cause, injury intent, and disposition at emergency department discharge (non-fatal data only). National mortality data from 1999 (the latest reporting year available) were based on the National Vital Statistics System of the National Center for Health Statistics, CDC. ${ }^{4}$ Annual non-fatal national estimates of hospital emergency department visits were based on the National Electronic Injury Surveillance System-All Injury Program (NEISS-AIP), which is a probability sample representative of US emergency departments for the first 12 months of available data, July 2000 through June 2001.5-8 NEISS-AIP is a collaborative effort between the National Center for Injury Prevention and Control, CDC and the US Consumer Product Safety Commission.

We reviewed data for children younger than 15 years of age to determine the leading causes of fatal and non-fatal injury,

regardless of intent. For each cause, we assessed cause specific lethality by computing the ratio of non-fatal injuries (expressed as injury related emergency department visits; IEDV) to the number of deaths (non-fatal to fatal ratio, NF:F). Age specific mortality rates were calculated using 1999 US Census Bureau population estimates. Non-fatal injury rates were calculated using the average US Census Bureau population estimates for 2000 and 2001, since the non-fatal data spanned two calendar years. Coefficients of variations and $95 \%$ confidence intervals around national estimates of numbers and rates were calculated using a direct variance estimation procedure that accounts for sample weights and the stratified sample design.

\section{RESULTS}

The 58.6 million US children younger than 15 years of age accounted for an estimated 7.1 million IEDV (95\% confidence interval 6.0 to 8.3 million) and 7365 injury deaths during a 12 month period. This resulted in an overall NF:F of 966 IEDV:1 death.

The leading causes of pediatric fatalities and non-fatal IEDV differed substantially (table 1). Among injury related fatalities, those related to motor vehicle traffic occupant deaths, inhalation/suffocations, and drownings accounted for $50 \%$ of all deaths. The respective NF:F for motor vehicle traffic occupants and suffocations were 150:1 and 14:1. Drownings accounted for 971 deaths and was the most lethal cause (NF:F $=6: 1)$. Among non-fatal injuries, falls were the leading cause, with more than 2.4 million IEDVs. This was almost $40 \%$ higher

Abbreviations: CDC, Centers for Disease Control and Prevention; GES, National Automotive Sampling System General Estimates System; ICD International Classification of Diseases; IEDV, injury related emergency department visits; NEISS-AIP, National Electronic Injury Surveillance System-All Injury Program; NF:F, non-fatal to fatal ratio; NHAMCS, National Hospital Ambulatory Medical Care Survey; WISQARS, Web based Injury Statistics and Query System 
Table 1 Leading cause of injury related emergency department visits (IEDV) and injury related deaths, ages 0-14, US

\begin{tabular}{|c|c|c|c|c|c|}
\hline $\begin{array}{l}\text { IEDV } \\
\text { rank }\end{array}$ & $\begin{array}{l}\text { Fatal } \\
\text { rank }\end{array}$ & Injury cause & No of IEDV* & $\begin{array}{l}\text { No of } \\
\text { fatalitiest }\end{array}$ & IEDV/1 death \\
\hline 1 & 10 & Fall & 2413888 & 127 & 19007 \\
\hline 2 & 11 & Struck by/against & 1757870 & 114 & 15420 \\
\hline 3 & 15 & Overexertion & 448303 & 0 & - \\
\hline 4 & 13 & Cut/pierce & 433017 & 56 & 7732 \\
\hline 5 & & Bites/stings $¥$ & 431147 & - & - \\
\hline 6 & 8 & Pedal cyclists§ & 321000 & 173 & 1855 \\
\hline 7 & 1 & MV traffic occupant \| & 254767 & 1700 & 150 \\
\hline 8 & & Foreign body $\uparrow$ & 228308 & - & - \\
\hline 9 & 7 & Other transportation * * & 169875 & 241 & 705 \\
\hline 10 & 5 & Fire/burn & 135707 & 686 & 198 \\
\hline 11 & 9 & Poisoning & 122432 & 130 & 942 \\
\hline 12 & 4 & Pedestriant† & 49310 & 733 & 67 \\
\hline 13 & 2 & Inhalation/suffocation & 14188 & 1037 & 14 \\
\hline 14 & 6 & Gunshot/firearm $\neq \ddagger$ & 12153 & 489 & 25 \\
\hline 15 & 3 & Drowning/near-drowning & 6102 & 971 & 6 \\
\hline 16 & 14 & Machinery & 4199 & 22 & 191 \\
\hline \multirow[t]{3}{*}{17} & 12 & Natural/environment & 3467 & 96 & 36 \\
\hline & & Other/unspecified/unknown & 306047 & 1031 & 297 \\
\hline & & All & 7111780 & 7365 & 966 \\
\hline
\end{tabular}

*Estimates based on NEISS-AIP data (July 2000 to June 2001).

tBased on 1999 National Vital Statistics data.

¥In WISQARS fatal data are included with natural/environment.

§lncludes all pedal cylcists (traffic, non-traffic, unspecified).

\|Non-fatals include only motor vehicle (MV) traffic occupants (excludes non-traffic and unknowns), fatals

include MV traffic occupant and unspecified traffic fatalities, of which most were occupant related. ${ }^{12}$

IIn WISQARS fatal data are included with suffocation.

** Includes motorcycle, railway, and air transport crashes.

t†lncludes all pedestrians (traffic, non-traffic, unspecified).

¥\#lncludes handgun, rifle, shotgun, BB gun, and airgun.

than the second leading cause, struck by/against ( 1.8 million IEDVs); however, these two causes were substantially less lethal, with NF:F = 19 000:1 and 15 000:1, respectively. Overexertion accounted for 448000 IEDVs, but was not associated with any deaths.

Transportation related injuries, which included injuries to motor vehicle traffic occupants, pedal cyclists (principally bicyclists), and pedestrians, were an important cause of pediatric injury morbidity and mortality. In this age group, non-fatal pedal cycle injuries resulted in about $25 \%$ more IEDV than motor vehicle occupant injuries. Pedestrian injuries were the most lethal transportation cause (NF:F $=67: 1$ ).
Injury mortality rates and IEDV rates varied by age and cause (tables 2 and 3). Motor vehicle traffic occupant mortality rates were highest for infants and 14 year olds. Infants younger than 1 year and, to a lesser degree, children older than 13 years had high suffocation fatality rates. Drowning and pedestrian mortality rates were highest for children between 1 and 2 years of age. IEDV rates for falls were highest among children between 1 and 2 years of age. Struck by/against IEDV rates were highest among children between 1 and 3 years old, and after 11 years of age, it was the leading cause of IEDV. In contrast, overexertion IEDV rates generally increased with age. Among transportation related causes, motor vehicle

Table 2 Annual injury related fatality rates* per 100000 population by cause, ages 0-14, US, 1999

\begin{tabular}{lllllll}
\hline Age (years) & $\begin{array}{l}\text { MV traffic } \\
\text { occupant十 }\end{array}$ & $\begin{array}{l}\text { Inhalation/ } \\
\text { suffocation }\end{array}$ & Drowning & Pedestrians & Fire/burn & Firearms \\
\hline$<1$ & 4.48 & 14.06 & 2.25 & $0.34 \S$ & 1.39 & $0.21 \S$ \\
1 & 2.42 & 2.37 & 5.96 & 2.50 & 2.34 & $0.29 \S$ \\
2 & 2.50 & 1.12 & 4.07 & 1.84 & 2.32 & $0.45 \S$ \\
3 & 3.06 & 0.85 & 2.02 & 1.49 & 2.29 & $0.51 \S$ \\
4 & 2.39 & 0.60 & 1.35 & 1.30 & 2.00 & $0.47 \S$ \\
5 & 2.11 & $0.51 \S$ & 1.05 & 1.28 & 1.39 & $0.39 \S$ \\
6 & 2.31 & $0.30 \S$ & 1.04 & 1.32 & 0.96 & $0.38 \S$ \\
7 & 2.70 & $0.25 \S$ & 1.12 & 1.27 & 1.14 & $0.40 \S$ \\
8 & 2.87 & $0.38 \S$ & 1.00 & 1.18 & 0.90 & $0.49 \S$ \\
9 & 2.40 & $0.45 \S$ & 0.79 & 1.01 & 0.50 & $0.36 \S$ \\
10 & 2.43 & 0.67 & 0.77 & 0.84 & 0.84 & $0.27 \S$ \\
11 & 2.77 & 0.98 & 0.87 & 1.21 & 0.59 & 0.67 \\
12 & 2.42 & 1.25 & 1.01 & 0.83 & $0.44 \S$ & 1.14 \\
13 & 3.43 & 1.21 & 1.01 & 1.01 & $0.31 \S$ & 2.19 \\
14 & 5.42 & 2.00 & 0.98 & 1.49 & $0.39 \S$ & 4.37 \\
$0-14$ & 2.91 & 1.77 & 1.66 & 1.25 & 1.17 & 0.84 \\
\hline
\end{tabular}

* Rates calculated from 1999 National Vital Statistics data and 1999 population estimates.

tIncludes motor vehicle (MV) traffic occupants and unspecified traffic fatalities, of which most were occupant related.

\#lncludes all pedestrians (traffic, non-traffic, unspecified).

§Rate is unstable because of a sample size of fewer than 20 deaths. 
Table 3 Annual non-fatal injury rates* per 100000 population of emergency department visits by cause, ages 0-14, US, July 2000 to June 2001

\begin{tabular}{|c|c|c|c|c|c|c|c|c|c|c|}
\hline $\begin{array}{l}\text { Age } \\
\text { (years) }\end{array}$ & Falls & $\begin{array}{l}\text { Struck by/ } \\
\text { against }\end{array}$ & Overexertion & $\begin{array}{l}\text { Cut/ } \\
\text { pierce }\end{array}$ & $\begin{array}{l}\text { Bites/ } \\
\text { stings }\end{array}$ & $\begin{array}{l}\text { Pedal } \\
\text { cyclist† }\end{array}$ & $\begin{array}{l}\text { MV traffic } \\
\text { occupant‡ }\end{array}$ & $\begin{array}{l}\text { Foreign } \\
\text { body }\end{array}$ & $\begin{array}{l}\text { Other } \\
\text { transport }\end{array}$ & Fire/burn \\
\hline$<1$ & 3415 & 985 & 111 & 166 & 260 & $2 \S$ & 219 & 322 & 35 & 390 \\
\hline 1 & 7207 & 2872 & 574 & 642 & 1123 & 65 & 263 & 638 & 128 & 867 \\
\hline 2 & 6729 & 3390 & 610 & 684 & 1257 & 168 & 378 & 1005 & 223 & 374 \\
\hline 3 & 5165 & 2852 & 354 & 654 & 1056 & 237 & 397 & 917 & 236 & 304 \\
\hline 4 & 4372 & 2696 & 242 & 670 & 983 & 399 & 396 & 646 & 279 & 200 \\
\hline 5 & 4113 & 2818 & 233 & 640 & 848 & 504 & 359 & 484 & 255 & 174 \\
\hline 6 & 3734 & 2639 & 295 & 744 & 764 & 692 & 379 & 328 & 253 & 143 \\
\hline 7 & 3467 & 2768 & 301 & 736 & 714 & 699 & 471 & 307 & 229 & 148 \\
\hline 8 & 3488 & 2971 & 527 & 885 & 741 & 665 & 393 & 254 & 284 & 114 \\
\hline 9 & 3485 & 2858 & 758 & 785 & 677 & 800 & 466 & 245 & 306 & 123 \\
\hline 10 & 3633 & 3088 & 884 & 855 & 658 & 791 & 479 & 200 & 360 & 143 \\
\hline 11 & 3785 & 3508 & 1165 & 854 & 561 & 797 & 497 & 200 & 362 & 128 \\
\hline 12 & 3481 & 3749 & 1502 & 912 & 489 & 811 & 498 & 127 & 430 & 139 \\
\hline 13 & 3157 & 3790 & 1773 & 905 & 495 & 764 & 550 & 128 & 425 & 113 \\
\hline 14 & 2854 & 3885 & 2020 & 898 & 470 & 703 & 740 & 135 & 507 & 168 \\
\hline 0-14 & 4117 & 2998 & 765 & 738 & 735 & 547 & 434 & 389 & 290 & 231 \\
\hline
\end{tabular}

* Rates calculated from NEISS-AIP data (July 2000 to June 2001) and the average of 2000 and 2001 population estimates. tIncludes all pedal cyclists (traffic, non-traffic, unspecified).

FIncludes only motor vehicle (MV) traffic occupants (excludes non-traffic and unknowns).

$\S$ Rate is unstable because of a sample size $<20$ cases or coefficient of variation $>30 \%$.

occupant IEDV rates increased with age, while the pedal cycle IEDV rate was highest in those between 9 and 12 years.

\section{DISCUSSION}

This study indicated that for every pediatric injury related death approximately 1000 injured children received emergency department treatment. Stated in other terms, about $0.1 \%$ of children died from their injuries. Rates of IEDV and injury related mortality varied by cause of injury and age.

This study found that the large number of injuries caused by falls, struck by/against, and overexertion accounted for more than $60 \%$ of all pediatric IEDV, yet were rarely fatal. Fall injury rates were highest among infants who are vulnerable because of their limited coordination, exploratory nature, and potential home hazards, while struck by/against and overexertion injury rates were most pronounced in older children who tend to be more active and involved in sports.

Results from this analysis were comparable to those generated by other databases. While NEISS-AIP estimated that children younger than 15 years of age account for 7.1 million IEDV, data from the 1999 National Hospital Ambulatory Medical Care Survey (NHAMCS) estimated this as 8.2 million, ${ }^{9}{ }^{10}$ a $13 \%$ difference. The NHAMCS estimate would be expected to be higher because it includes repeat emergency department visits for the same injury incident and it includes cases where the reason for the visit was an injury as well as those with injury diagnoses, while the NEISS-AIP estimate includes only the initial emergency department visit for an injury incident and only those cases with injury diagnoses as determined by an attending physician. The other major surveillance systems available for comparing injuries and deaths relate to traffic crashes. The National Highway Traffic Safety Administration tallies traffic related fatalities using the Fatality Analysis Reporting System and estimates non-fatal traffic related injuries using the National Automotive Sampling System General Estimates System (GES). Compared with our results, the NF:F ratios generated by these systems were similar for motor vehicle traffic occupants, but substantially different for pedal cyclists and pedestrians. These differences are attributable to discrepancies in non-fatal injury data. Fatality Analysis Reporting System results are similar to the vital statistics fatality data ${ }^{11}$; however, the NEISS-AIP capture of non-fatal transportation injuries is more complete than GES. GES is based on police incident reports and includes only those crashes that occur in traffic and that are reported to the police. Compared with GES, ${ }^{12}$ NEISS-AIP records $7.1 \%$ more injured motor vehicle occupants, $60 \%$ more traffic related pedestrians injured, and over four times more traffic related pedal cyclists injured.

The fatal and non-fatal injury related databases used in our analysis provide timely data for the injury pyramid. These databases can be used to indicate the annual incidence of the top three levels of the injury pyramid, namely deaths, hospitalizations, and emergency department visits. These databases cannot be used to indicate the bottom level of the pyramid: total episodes of injuries (including those untreated). Hospitalization estimates can be determined from the emergency department disposition field; however, with the 12 months of data for this analysis, we did not address the issue of hospitalizations because the estimates can be unstable for less common injuries. A more detailed analyses of hospitalizations by external cause and intent of injury will be possible as more years of NEISS-AIP data become available.

This study has several limitations. First, the injuries included only those treated in hospital emergency departments; injuries that were treated in outpatient clinics or doctors' offices, or not medically treated were not included. Second, the NEISS-AIP provides only national estimates and does not allow for estimates by region, state, or local jurisdiction. Third, non-fatal causes were based on International Classification of Diseases (ICD)-9 codes $^{8}{ }^{12}{ }^{13}$ while fatal data were based on ICD-10 codes. ${ }^{14}$ ICD-10 is more detailed, with 3000 more categories for all causes of death, and some of the rules for coding and for selecting the underlying cause of death have been changed to favor case ascertainment of injury. ${ }^{15}$ However, when analyzing the ICD-9 based 1998 mortality data, there were only minor differences in injury cause rankings and rates. Finally, these mortality and morbidity data were compared for different time periods. However, given the magnitude of these findings, our results would not likely differ if the same year of data had been available for both fatal and non-fatal injuries.

\section{IMPLICATIONS FOR PREVENTION}

Public health policy has been largely influenced by mortality data. New nationally based interactive databases now permit public health professionals to fully consider the importance of non-fatal injuries in developing priorities.

While our study indicated that falls constitute a large proportion of non-fatal injuries among children, causal factors 


\section{Key points}

- Although less devastating than deaths, non-fatal injuries occurred much more frequently, and their leading causes differed. For every pediatric injury death, approximately 1000 injured children received emergency department treatment.

- Among children, the leading causes of fatal injuries differed from leading causes of non-fatal injuries, indicating the need to consider causes of non-fatal injuries when prioritizing public health research and programs.

- Falls accounted for over 2.4 million pediatric emergency department visits and struck by/against accounted for 1.8 million pediatric emergency department visits each year. Further study into the etiologic factors is warranted to identify areas amenable to preventive measures.

such as playgrounds, sports, falls from beds or furniture, stairs, or falls from heights could not be determined. Development of preventive measures to address falls will require a better understanding of these etiologic factors.

\section{Authors' affiliations}

M F Ballesteros, Epidemic Intelligence Service, Division of Applied Public Health Training, Epidemiology Program Office and Division of Unintentional Injury Prevention, National Center for Injury Prevention and Control, Centers for Disease Control and Prevention, Atlanta, Georgia R A Schieber, J Gilchrist, Division of Unintentional Injury Prevention, National Center for Injury Prevention and Control, Centers for Disease Control and Prevention, Atlanta, Georgia

P Holmgreen, J L Annest, Office of Statistics and Programming, National Center for Injury Prevention and Control, Centers for Disease Control and Prevention, Atlanta, Georgia

\section{REFERENCES}

1 Centers for Disease Control and Prevention. Available at: http://webapp.cdc.gov/sasweb/ncipc/leadcaus.html (accessed on 2 January 2002).
2 Fingerhut LA, Warner M. Injury chartbook, health, United States, 1996-97. Hyattsville, MD: National Center for Health Statistics, 1997.

3 Freid VM, Makuc DM, Rooks RN. Ambulatory health care visits by children: principal diagnosis and place of visit. Vital Health Stat 13 1998;13(137): 1-23.

4 Murphy SL. Deaths: final data for 1998. National vital statistics reports. Hyattsville, MD: National Center for Health Statistics, 2000.

5 US Consumer Product Safety Commission. National Electronic Injury Surveillance System (NEISS) coding manual. Washington, DC: US Consumer Product Safety Commission, 1997.

6 Centers for Disease Control and Prevention. National estimates of nonfatal injuries treated in hospital emergency departments - United States, 2000. MMWR Morb Mortal Wkly Rep 2001;50(17):340-6.

7 US Consumer Product Safety Commission. The NEISS sample: design and implementation. Washington, DC: US Consumer Product Safety Commission, 2000.

8 Quinlan KP, Thompson MP, Annest JL, et al. Expanding the National Electronic Injury Surveillance System to monitor all nonfatal injuries treated in US hospital emergency departments. Ann Emerg Med 1999:34:637-45

9 McCaig LF, Burt CW. National hospital ambulatory medical care survey: 1999 emergency department summary. Advance data from vital and health statistics. Hyattsville, MD: National Center for Health Statistics, 2001.

10 McCaig LF, Mclemore T. Plan and operation of the national hospital ambulatory medical survey. Series 1: programs and collection procedures. Vital Health Stat 1 1994(34): 1-78.

11 Centers for Disease Control and Prevention. Recommended framework for presenting injury mortality data. MMWR Morb Mortal Wkly Rep 1997;46(RR-14):20-3.

12 National Highway Traffic and Safety Administration. Traffic safety facts 2000: a compilation of motor vehicle crash data from the Fatality Analysis Reporting System and the General Estimates System. Washington, DC: Department of Transportation, 2001.

13 National Center for Health Statistics. Official ICD-9-CM guidelines for coding and reporting. Hyattsville, MD: National Center for Health Statistics, 1997.

14 World Health Organization. International classification of diseases and related health problems: 10th revision. Geneva, Switzerland: WHO, 1992.

15 Anderson RN, Minino AM, Hoyert DL, et al. Comparability of cause of death between ICD-9 and ICD-10: preliminary estimates. Natl Vital Stat $\operatorname{Rep} 2001 ; 49(2): 1-32$ 